\title{
Investigation of passive radar target detection performance improvement by using multiple co-located FM radio transmitters
}

\author{
Pasif radar hedef tespit performansinin iyileştirilmesi için çoklu ortak FM \\ radyo vericilerin kullanılmasının araştırılması
}

\author{
Burak TUYSUZ ${ }^{*}$ iD \\ 1Department of Engineering, Engineering Faculty, Recep Tayyip Erdogan University, Rize, Turkey. \\ burak.tuysuz@erdogan.edu.tr
}

Received/Geliș Tarihi: 08.05.2018, Accepted/Kabul Tarihi: 21.09.2018

* Corresponding author/Yazışılan Yazar

doi: $10.5505 /$ pajes.2018.92693

Research Article/Araștırma Makalesi

\begin{abstract}
Interest in passive radar systems is increasing because of its hidden operational capabilities, cost effectiveness and low maintenance requirements. The greatest advantage of these systems is that they can detect and follow targets using the illuminators in the environment without the need for a dedicated transmitter. In recent years, the increasing number of wireless transmitters have begun to be gathered at a single point, creating new opportunities for passive radar systems. In this study, target detection performance in passive radar systems by using multiple frequency FM radio broadcasts from a common transmitter point is investigated. Accordingly, a real-time applicable method proposed that combines the singular channels on a broad frequency band with software based radio technologies to improve target detection performance. It has been shown that the proposed method improves the target detection performance of FM signals without introducing additional load to the system and reduces the performance fluctuations and ghost targets that are generated in passive radar systems due to the modulation content
\end{abstract}

Keywords: Passive radar, FM radio, Multiple transmitter, Target detection, Software defined radio

\section{Introduction}

Nowadays, wireless broadcasters, which are increasing in number, can lead to electromagnetic pollution and indirect health problems [1]. In addition, due to these transmitters, visual pollution also occur. Especially in recent years, studies have been carried out to solve these problems by placing transmitters in a region or deploying them on a dominant tower. Remote sensing systems that operate using the emitted signals by these wireless transmitters can be developed. In addition, the performance of the remote sensing systems can be improved by making use of these co-located transmitters. Passive radars are a good candidate to take the advantage of the co-located transmitters. These systems do not have a dedicated transmitter but can detect and track targets using broadcasts of commercial transmitters such as FM, TV, GSM etc. [2] Increasing number of wireless transmitters and declining unit processing costs keep the interest on passive radar systems alive [3]-[5]. Additionally, among these various types of transmitters, employment of FM transmitters in passive radars is still very popular because of being widespread, having high output powers and nearly perfect ambiguity of the transmitted signals. A typical passive radar system has at least two receivers as shown in Figure 1.
Öz

Gizli operasyon kabiliyeti, uygun maliyet ve düșük bakım gereksinimi gibi özellikleri nedeniyle pasif radar sistemlerine olan ilgi giderek artmaktadır. Bu sistemlerin en büyük avantajı ise kendilerine ait bir vericiye ihtiyac duymadan ortamda bulunan vericileri kullanarak hedef tespit ve takibi yapabilmeleridir. Son yıllarda sayıları artan kablosuz iletișim vericilerinin tek bir noktada toplanmaya bașlanması ise pasif radar sistemleri için yeni firsatlar yaratmaktadır. Bu çalıșmada, ortak bir verici noktasindan, birden çok frekansta yapılan FM radyo yayınların birlikte kullanılmasıly a pasif radar sistemlerinde hedef tespit performansının arttırılması araştırılmıştır. Önerilen yöntem sayısallaștırılan geniș bir frekans bandından ayrıștırılan tekil kanalların yazılım tabanlı radyo teknolojileri ile toplanarak hedef tespit performansının artırılmasını sağlamaktadır. Gerçek FM radyo verileri ile yapılan testlerde önerilen yöntemin sisteme ek yük getirmeden hedef tespit performansını artırdığı, modülasyon içeriği sebebiyle pasif radar sistemlerinde oluşan performans dalgalanmalarını ve olușan hayalet hedefleri azalttığı görülmüștür.

Anahtar kelimeler: Pasif radar, FM radyo, Çoklu verici, Hedef tespit, Yazılım tabanlı radyo

As can be seen in the figure one of these receivers is referred to as a reference receiver and is responsible for collecting high signal-to-noise ratio copies of the signals emitted from the transmitter. The other receiver is called surveillance receiver and ideally it only collects the reflections from the target. By processing the data collected from these two receivers, it is possible to detect and track targets. One of the major disadvantages of passive radar systems is the dependency on third party transmitters. The bandwidth of the transmitted signal limits the range resolution, while the output power restricts detection range. At the same time, the modulation content of the utilized transmitter cause fluctuations in passive radar performance [6].

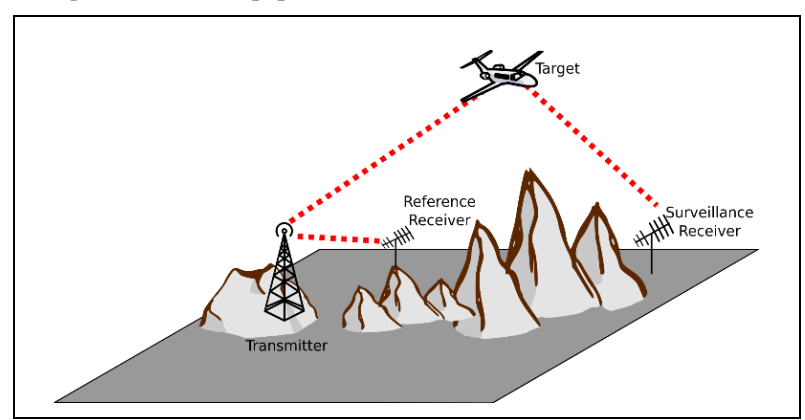

Figure 1: A basic passive radar geometry. 
In passive radar systems where the transmitters are not under the control of the radar operator, the target detection performance can be improved by using multiple co-located transmitters together to overcome these disadvantages.

There are various studies in the literature on performance improvement with the use of multiple transmitters [7]-[9]. In these studies, the usual approach was to generate multiple target detection surfaces by using individual transmitters and linearly adding them. In these proposed methods, the use of individual transmitters and the creation of separate rangeDoppler frequency surfaces double the signal processing cost for each channel. In another approach, the detected targets were compared with the data obtained from different transmitters and the false target detection performance was improved accordingly [7]. However, this approach is not suitable for real-time applications due to the additional signal processing costs it requires. Additionally, in a recent study, the range resolution of the passive radar systems was improved by employing using successive FM channels [10]. However, the proposed approach remained as a theoretical study because of the applicability issues on finding consecutive FM transmitters with antennas directed in the same direction.

In this study, unlike the examples in the literature, a method that can be used in practical scenarios in order to improve the target detection performance of FM radio based passive radar systems is proposed. The proposed method does not introduce additional heavy signal processing steps and can be used with the co-located transmitters on non-consecutive frequencies. Additionally, multiple channels receivers are not required and a single channel receiver is sufficient for the operation. In the proposed method a wide frequency band is digitized and individual channels separated and summed linearly in the time domain to improve target detection performance. In this paper, a $10 \mathrm{MHz}$ FM frequency band with multiple FM transmitters is digitized using software-based radio equipment and libraries. In this frequency band, two individual FM stations which are known being co-located and transmitting with the same antenna direction are separated and simultaneously added in the time domain to obtain the final data for target detection. The target detection performance of data from individual FM stations is compared to the final data obtained by the summation of these individual stations.

The rest of the paper is formed as follows: in section two, the data collection steps software-based radio is given. Additionally, the ambiguity function analysis of these data is realized. In the third section, the target detection performance of the datasets on the range-Doppler frequency surfaces is investigated. The results are drawn in the last section.

\section{Materials and methods}

In this section, first the software defined radio hardware employed to collect data is explained in detail. Then the creation of datasets are explained with self-ambiguity function analysis for further target detection performance analysis.

\subsection{Software defined radio and data collection}

Software-based radio is a radio communication system in which traditional hardware components (mixers, filters, amplifiers, modulators/demodulators, detectors, etc.) are implemented in software [11]. The fact that the signal processing stages are software-based makes the developed systems cost- effective and flexible. In this study, USRP N210 software defined radio equipment and GNU Radio software defined radio library is used to digitize and process data [12],[13]. The USRP N210 software defined radio hardware has two $100 \mathrm{MHz}$ analog to digital converter (ADC). Also, there is a Field Programmable Gate Array (FPGA) on the board for the signal processing of high speed signals without losing data. The data is transferred to the computer via the ethernet port after decimation and filtering operations to reduce the data speed. Additionally, it is possible to cover frequency range from DC to $4400 \mathrm{MHz}$ by changing daughterboards.

The accompanying GNU Radio software is a software-based radio tool which is an open-source library based on block structures. Beside the existing signal processing blocks in the library, users can develop additional signal processing blocks. The performance critical parts of the library are written in $\mathrm{C}++$ and the rest are coded in Python programming language which makes real-time signal processing flexible and cost effective.

In this study, it is aimed at FM radio signals, which are widely available with reasonably high output power levels, for target detection performance improvement. The usual bandwidth of FM stations are around $100 \mathrm{kHz}$ and they are found to be useful for passive radar applications [14],[15]. However, because of the narrow bandwidth and changing modulation content, range resolution is poor and the target detection performance fluctuates. The proposed method suggests employing more than one FM radio broadcast for target detection performance improvement. Thus, it is required to digitize a wide band to capture the radio stations. In Figure 2, a $10 \mathrm{MHz}$ portion of an FM frequency spectrum from $90 \mathrm{MHz}$ to $100 \mathrm{MHz}$ is shown. As can be seen in the figure, there are four strong FM stations transmitting at $92 \mathrm{MHz}, 94.6 \mathrm{MHz}, 95 \mathrm{MHz}$ and $97 \mathrm{MHz}$. Among these stations, the signals at $92 \mathrm{MHz}$ and $97 \mathrm{MHz}$, which are known to be co-located are selected for testing the proposed method. The recently developed PIRE radar system is used for the generation of real FM datasets [16]. The FM broadcaster at $92 \mathrm{MHz}$ is sampled at $100 \mathrm{kS} / \mathrm{s}$ for 5 seconds and this data is labeled as dataset 1 . Simultaneously, the FM broadcaster at $97 \mathrm{MHz}$ is sampled at $100 \mathrm{kS} / \mathrm{s}$ for 5 seconds and labeled as dataset 2 . The dataset 3 is constructed by the summation of two datasets which produces a data at the same length with dataset 1 and dataset 2 .

The proposed method is intended to improve operational capabilities of real systems thus it is required to construct the summation of two or more FM broadcasters in real-time. A simple and effective solution is proposed as follows. For the current setup, which is the sampling of $10 \mathrm{MHz}$ bandwidth, the center frequency of the digitized spectrum is at $95 \mathrm{MHz}$ which is $2 \mathrm{MHz}$ ahead of the $\mathrm{FM}$ radio broadcaster at $97 \mathrm{MHz}$ station and $3 \mathrm{MHz}$ behind the FM radio broadcaster at $92 \mathrm{MHz}$. These individual stations are separated from the wideband digitized spectrum and decimated for $100 \mathrm{kHz}$ bandwidth and added together to get a single $100 \mathrm{~Hz}$ channel as shown in Figure 3. As can be seen in the figure USRP source block centered at $95 \mathrm{MHz}$ is sampling analog signals at $10 \mathrm{MS} / \mathrm{s}$ and then sending the digitized data to the Frequency Xlating Filter block. The Frequency Xlating Filter block applies frequency translation on the signal and then downsamples by running a decimating finite impulse response filter on it. As a result, Frequency Xlating Filter blocks separate the stations at $92 \mathrm{MHz}$ and $97 \mathrm{MHz}$ with $100 \mathrm{kHz}$ bandwidth. Finally, these two stations are added together and the resulting $100 \mathrm{kHz}$ signal is saved to a file in the File Sink. This signal processing structure can be used in a real-time system without causing any performance degradation. 


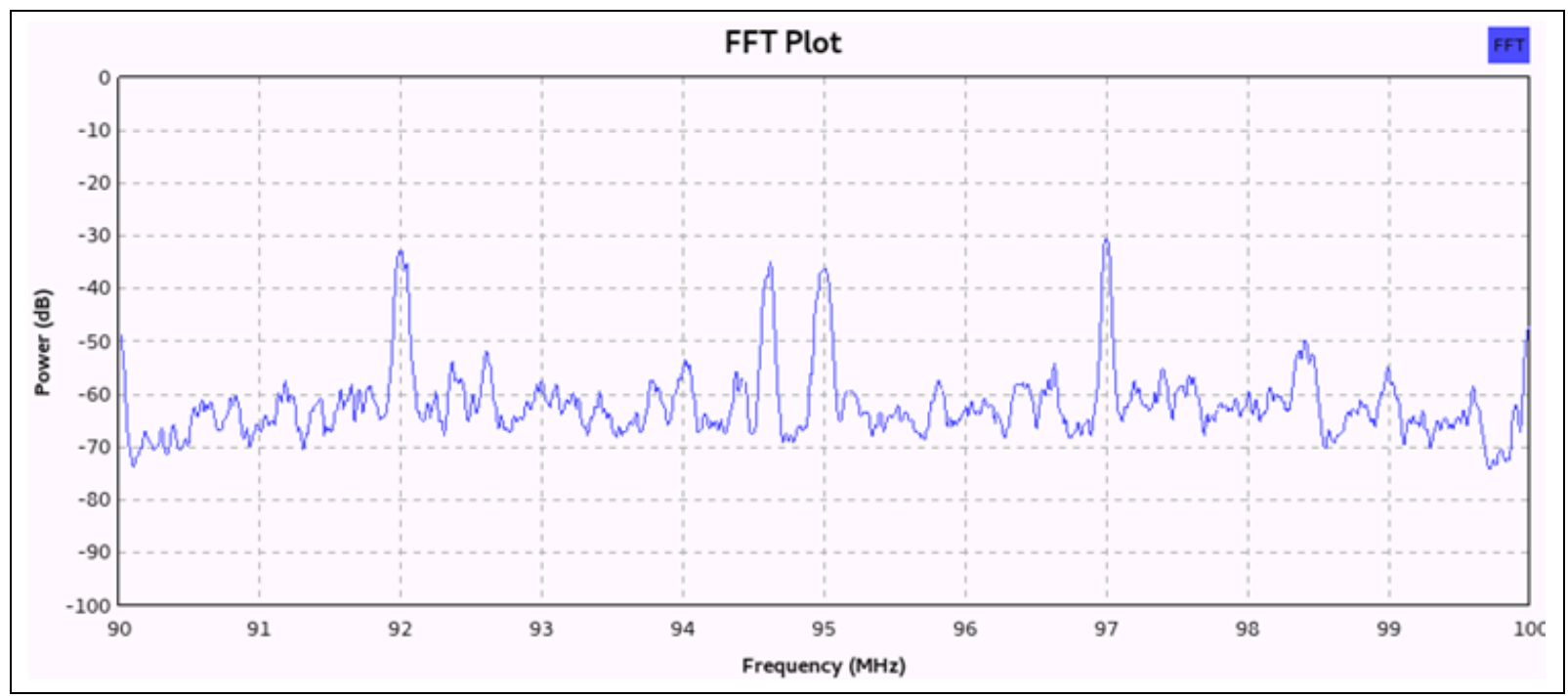

Figure 2: Instantaneous frequency power spectrum of the FM radio band from $90 \mathrm{MHz}$ to $100 \mathrm{MHz}$.

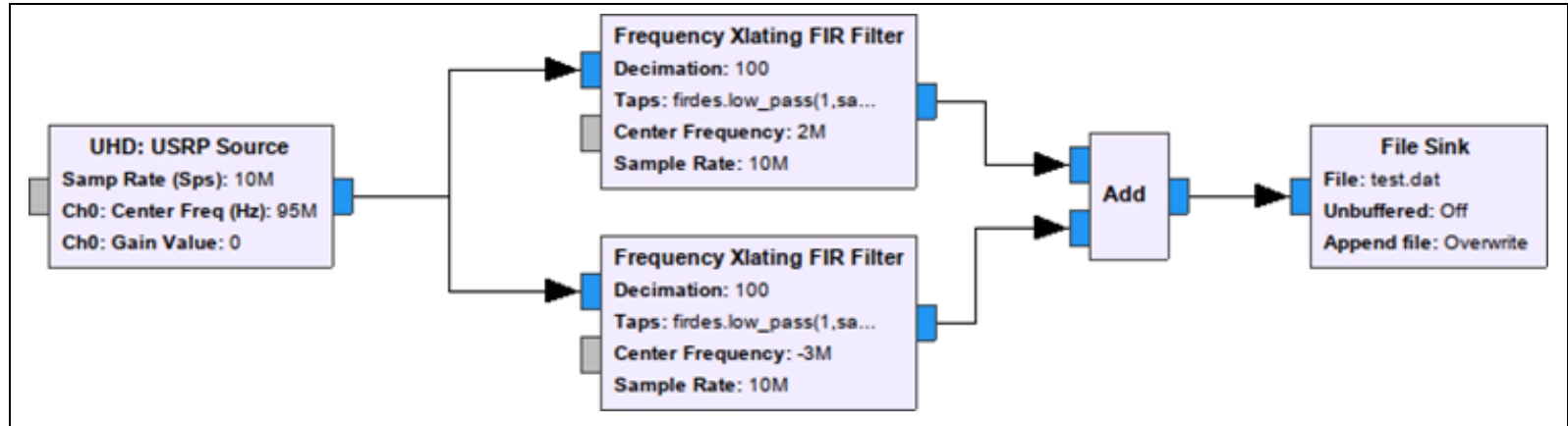

Figure 3: GNU Radio block diagram for the real-time generation of the proposed data stream with multiple channels.

\subsection{Analysis of the self-ambiguity functions}

Doppler frequency and range resolution of a radar signal can be calculated by using theoretical equations. However, in passive radar systems, because of the varying modulation content, selfambiguity function analysis can be used to estimate range and Doppler frequency resolution [17]. Ambiguity function can be defined as

$$
\chi(\tau, f)=\int_{-\infty}^{\infty} s(t) s^{*}(t-\tau) e^{i 2 \pi f t} d t
$$

Where, $s(t)$ is the signal to be analyzed, $\tau$ is the time delay and $f$ is the Doppler frequency shift. In this two dimensional function, if the signal is ambiguous in itself, a single peak at $\chi(0,0)$ will be expected. The extension of the main peak at $\chi(0,0)$ on Doppler frequency and time delay axis is used to define the range and Doppler speed resolution of the target signal [18]. In this study, first, the self-ambiguity function analysis of the individual radio stations on $92 \mathrm{MHz}$, dataset 1 , and $97 \mathrm{MHz}$, dataset 2, is investigated. Then, dataset 3, which is generated by using these two datasets is analyzed. In Figure 4, the self-ambiguity function of dataset 1 , which is the transmission from the $\mathrm{FM}$ radio broadcaster at $92 \mathrm{MHz}$ sampled at $100 \mathrm{kS} / \mathrm{s}$ for $5 \mathrm{sec}$, is given. The single main peak at the center of the ambiguity function indicates good ambiguous properties within the signal. In addition, side peaks due to FM modulation are visible at $-100 \mathrm{~Hz}$ and $100 \mathrm{~Hz}$. In Figure $4 \mathrm{~b}$ and Figure 4c, from the graphs of the range and Doppler frequency cuts, it can be seen that the range resolution is about $5 \mathrm{~km}$ and the Doppler frequency resolution is about $1 \mathrm{~Hz}$. In the range cut, the peak to side ratio is approximately $41 \mathrm{~dB}$ and the peak to side ratio in the Doppler frequency cut is approximately $31 \mathrm{~dB}$.

In Figure 5, self-ambiguity function and axis cuts are given for dataset 2, which is from the FM transmitter broadcasting at 97 $\mathrm{MHz}$ sampled at $100 \mathrm{kS} / \mathrm{s}$ for $5 \mathrm{sec}$. In the given figure, correlation peak in the center and the side peaks due to FM modulation can also be observed at $-100 \mathrm{~Hz}$ and $100 \mathrm{~Hz}$. Accordingly, Figure $5 b$ and Figure $5 c$ show graphs of range and Doppler frequency cuts of the self-ambiguity function. It can be observed that the range resolution is approximately $5 \mathrm{~km}$ and the Doppler frequency resolution is approximately $1 \mathrm{~Hz}$. In this particular data, the range cut peak to side ratio is about $45 \mathrm{~dB}$ and the Doppler frequency cut peak to side ratio is about $29 \mathrm{~dB}$.

The self-ambiguity function of generated dataset 3 is shown in Figure 6. Visual comparison of the self-ambiguity function given in Figure 6a shows that it has better resolution properties compared to the self-ambiguity functions given in Figure 4a and Figure $5 \mathrm{a}$. In the range cut of the self-ambiguity function given in Figure 6b, it can be seen that the side peaks approach the noise floor. In the Doppler frequency cut of the self-ambiguity function shown in Figure 6c, the peak to side ratio is about $33 \mathrm{~dB}$ which is better than that of the individual broadcasts shown in Figure 4c and Figure 5c. The impacts of this case on target detection performance are examined in the next section. 


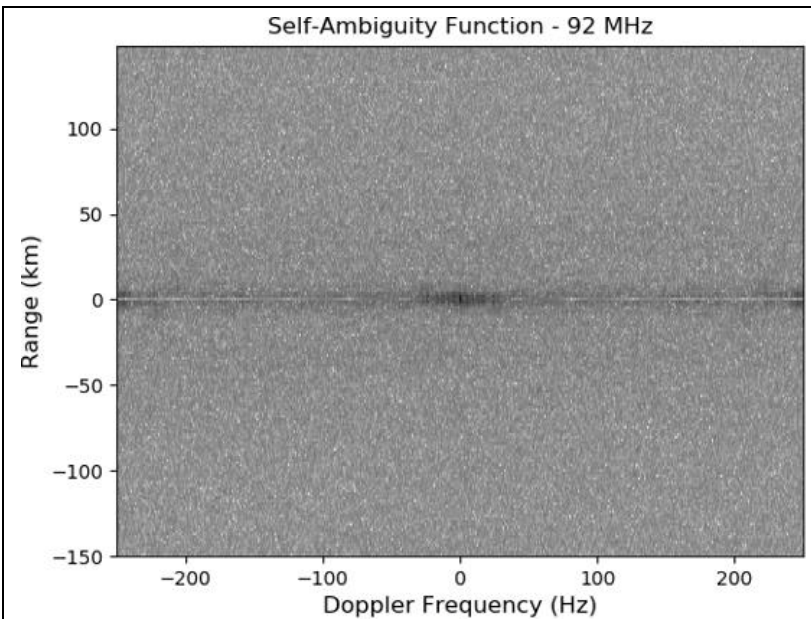

a)

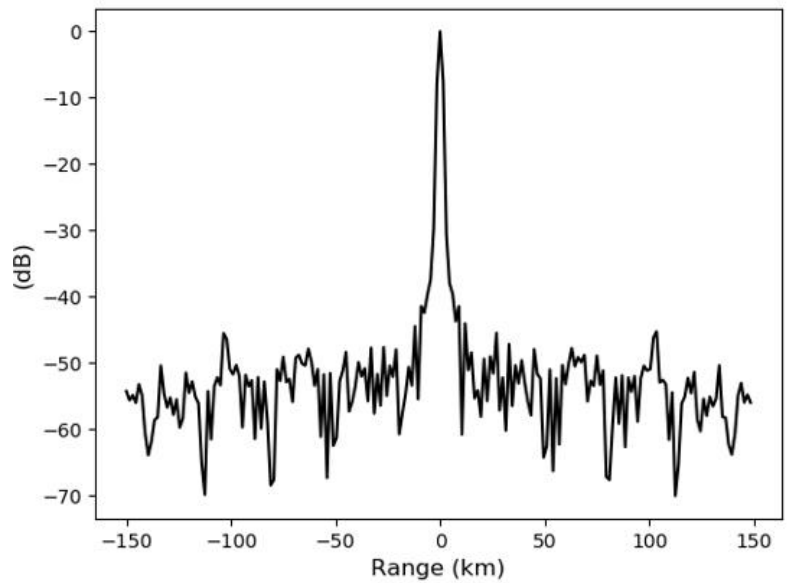

b)

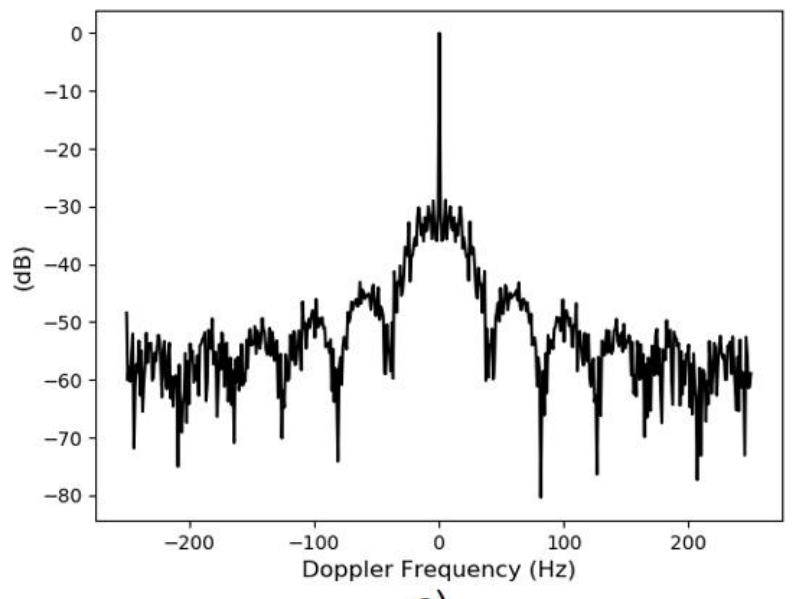

c)

Figure 4: The self-ambiguity function of the dataset 1 , data captured at $92 \mathrm{MHz}$ for $5 \mathrm{sec}$. at $100 \mathrm{kS} / \mathrm{s}$ sampling rate.

(a): 3-D representation of the self-ambiguity function,

(b): Self-ambiguity function range cut, (c): Self-ambiguity function Doppler frequency cut.

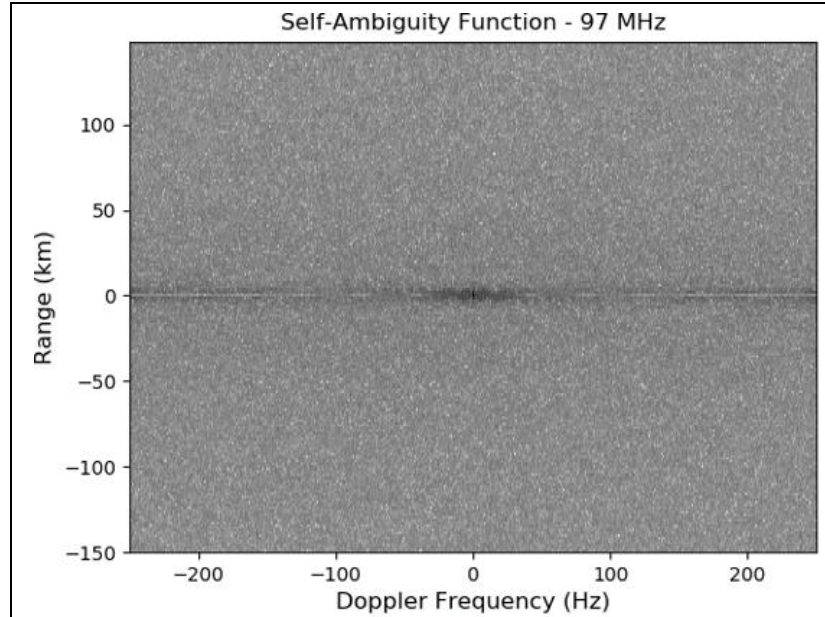

a)

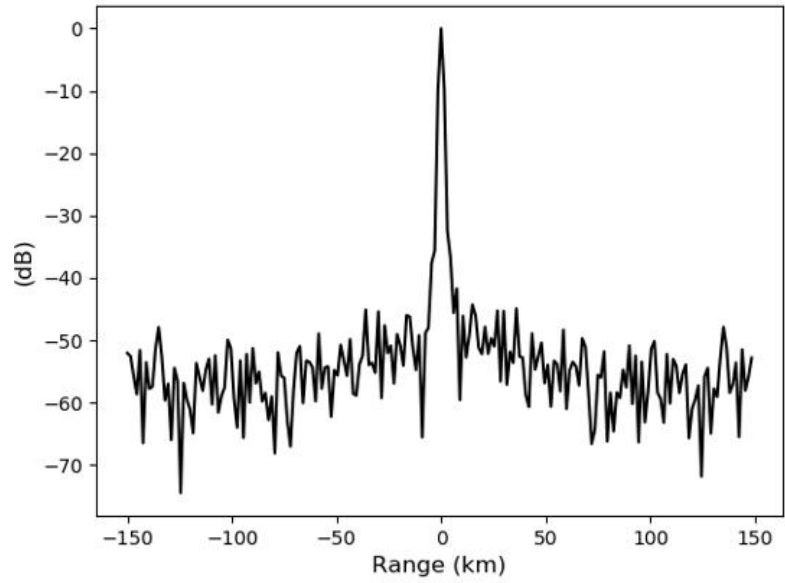

b)

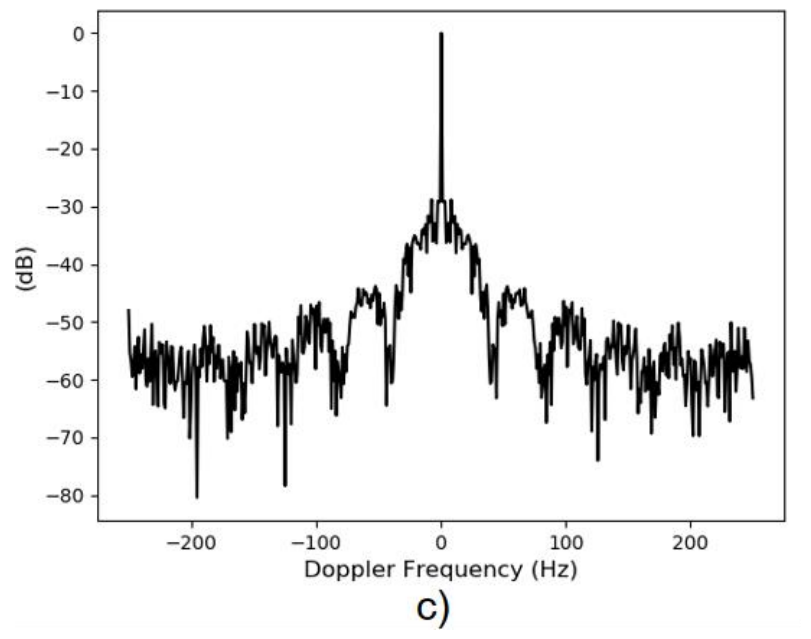

Figure 5: The self-ambiguity function of the dataset 2, data captured at $97 \mathrm{MHz}$ for $5 \mathrm{sec}$. at $100 \mathrm{kS} / \mathrm{s}$ sampling rate.

(a): 3-D representation of the self-ambiguity function,

(b): Self-ambiguity function range cut, (c): Self-ambiguity function Doppler frequency cut. 


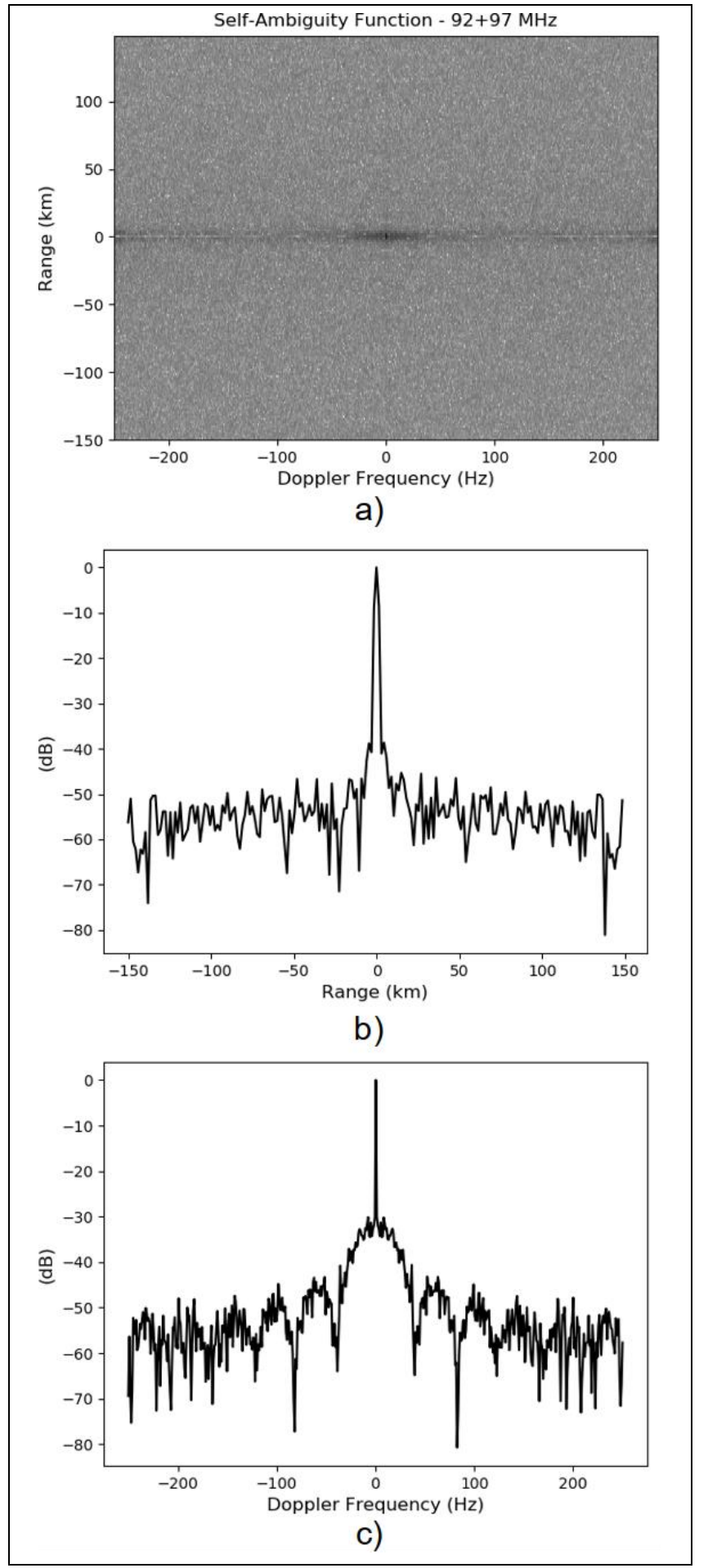

Figure 6: The self-ambiguity function of the dataset 3 , data composed by linearly adding captured data from $92 \mathrm{MHz}$ and $97 \mathrm{MHz}$. (a): 3-D representation of the self-ambiguity function,

(b): Self-ambiguity function range cut, (c): Self-ambiguity function Doppler frequency cut.

\section{Target detection performance comparison}

In this section, the target detection performance of the data sets by including virtual targets on the data are investigated. First, virtual targets are added to the data sets then by generating the range-Doppler frequency surfaces, target detection performances are compared. In passive radar systems, generation of the Range-Doppler frequency surfaces can be achieved by employing cross ambiguity function which can be defined as;

$$
|A(\tau, \vartheta)|=\left|\int_{-\infty}^{\infty} s_{\text {surveillance }}(t) s_{\text {reference }}(t-\tau)^{*} e^{-j 2 \pi \vartheta t} d t\right|^{2}
$$

In the given equation, $|A(\tau, \vartheta)|$ is the cross ambiguity function, $\mathrm{s}_{\text {reference }}$ is the signal from the reference receiver, $\mathrm{s}_{\text {surveillance }}$ is the signal from the surveillance receiver and $\tau$ and $\vartheta$ are the time delay and Doppler frequency, respectively. The cross ambiguity function tests the correlation between the reference and surveillance signal by shifting the reference signal in time for different Doppler frequency shifts [19].

Four different virtual targets are injected on each dataset for the comparison of target detection performance. The properties of the virtual targets are given in Table 1 . As can be seen from the table, the injected targets have distinct properties. For instance, the Target 1 has $-30 \mathrm{~dB}$ attenuation at $20 \mathrm{~km}$ range and $30 \mathrm{~Hz}$ Doppler frequency. Other targets have similar attributes and are distributed on the range-Doppler frequency surface.

Table 1: Properties of the virtual targets included on data sets.

\begin{tabular}{cccc}
\hline & $\begin{array}{c}\text { Range } \\
(\mathrm{km})\end{array}$ & $\begin{array}{c}\text { Doppler } \\
\text { Frequency }(\mathrm{Hz})\end{array}$ & $\begin{array}{c}\text { Attenuation } \\
(\mathrm{dB})\end{array}$ \\
\hline Target 1 & 20 & 30 & -30 \\
Target 2 & 20 & 120 & -30 \\
Target 3 & 100 & 100 & -32 \\
Target 4 & 250 & 50 & -33 \\
\hline
\end{tabular}

The virtual targets given in the table were first added to the dataset 1 . Accordingly, the range-Doppler frequency surface is generated with an integration time of $5 \mathrm{sec}$ as given in Figure 7. As can be seen in the figure, the strongest signal power at the generated detection surface is around $110 \mathrm{~dB}$. All the targets given in Table 1 can be observed on the detection surface. Additionally, there are some ghost target echoes caused by the modulation content which can lead to false positive detection [20]. Also, due to Doppler frequency scattering and generated ghost echoes, Target 1 and Target 2 are close in the frequency axis and can be perceived as a single target.

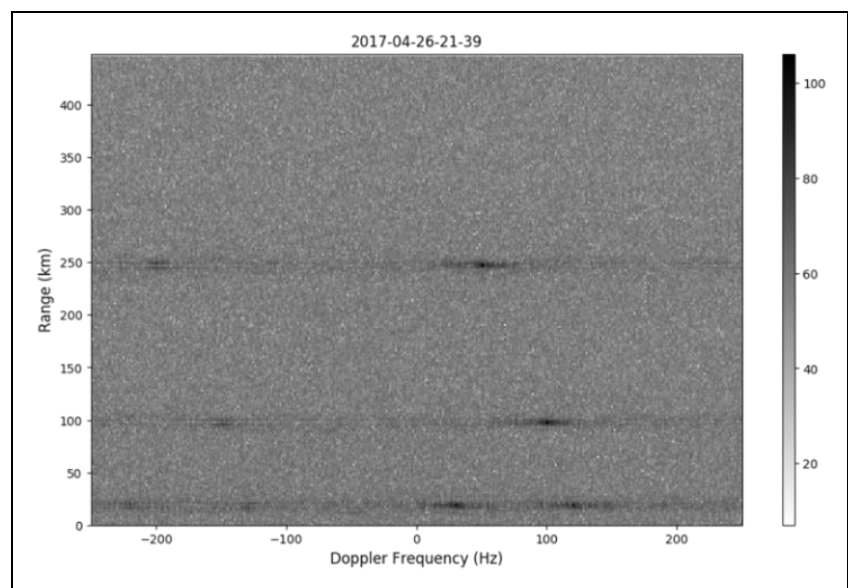

Figure 7: The range-Doppler frequency surface generated with the dataset 1 which is $92 \mathrm{MHz}$ FM data collected for 5 sec. 
The range-Doppler frequency surface generated for the dataset 2 , which is collected at $97 \mathrm{MHz}$ for 5 seconds is given in Figure 8. In the generated detection surface, the maximum signal power is observed as $110 \mathrm{~dB}$. However, the frequency dispersion on the target echoes are $10 \mathrm{~dB}$ lower compared to Figure 7. The dispersion on range axis is also lower compared to Figure 7. In general compared to dataset 1 which is collected on $92 \mathrm{MHz}$, dataset 2 shows better correlative properties.

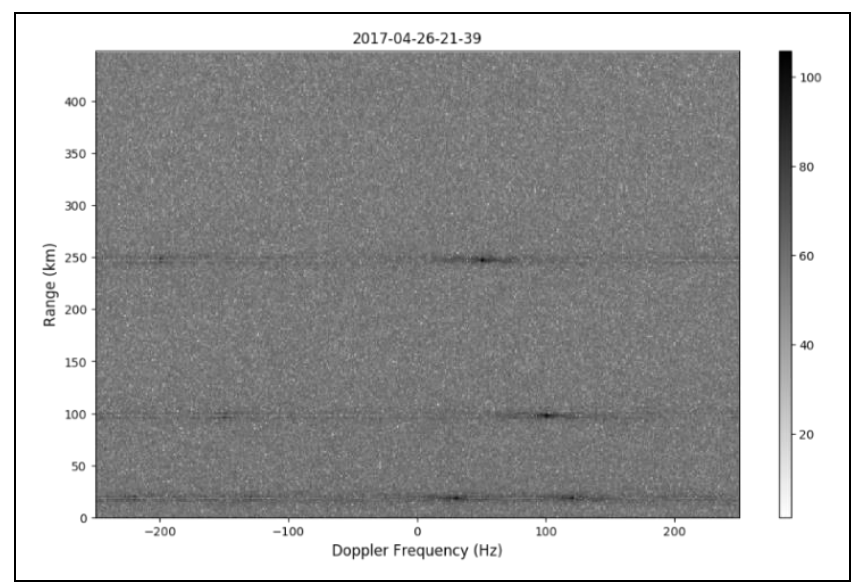

Figure 8: The range-Doppler frequency surface generated with the dataset 2 which is $97 \mathrm{MHz}$ FM data collected for $5 \mathrm{sec}$.

Ultimately the detection surface for the dataset 3 is generated as can be seen in Figure 9. This dataset also includes the same virtual targets which are seen in dataset 1 and dataset 2 . The most obvious improvement in the detection surface is the attenuation on ghost target echoes and the reduction on noise floor. The ghost target echoes are around $70 \mathrm{~dB}$ which is $50 \mathrm{~dB}$ below the strongest signal power on the detection surface. The maximum detected signal power level is measured as $120 \mathrm{~dB}$ which is $10 \mathrm{~dB}$ higher than Figure 7 and Figure 8. In particular, the attenuation of ghost target echoes and the improvement of the target echo dispersions are crucial for improving target detection performance. These improvement rates can also be enhanced by using more than two stations by the same proposed algorithm.

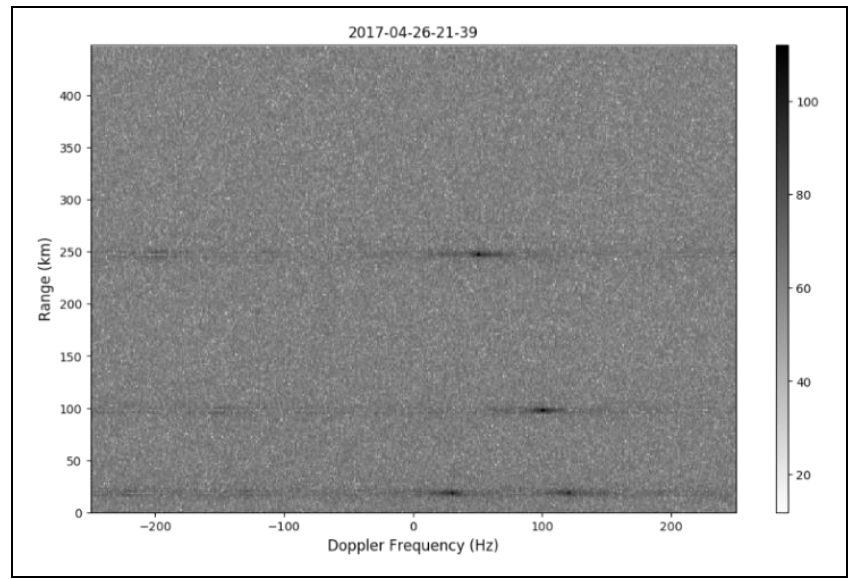

Figure 9: The Range-Doppler frequency surface of the dataset 3 with virtual targets.

\section{Conclusions}

Passive radar systems are among the most interesting topics of remote sensing because they enable cost effective target detection and tracking opportunities by employing the transmitters located in the environment. One of the biggest disadvantages of these systems is the fluctuation of performance due to the transmitter broadcast content. Especially FM radio broadcasts, which are very popular for passive radar applications because of the output power and being widespread, are susceptible to performance fluctuations. In this study, employment of more than one transmitter is proposed to improve the target detection performance on the passive radar systems. Using the proposed original method and software defined radio technologies, it has been shown that performance fluctuations of a single radio station due to modulation content can be reduced by using multiple transmitters without affecting current system performance and creating additional processing load. It is shown that, by employing two co-located FM transmitters, it is possible to reduce noise floor and ghost target echoes. The ghost target echoes are reduced $50 \mathrm{~dB}$ below the strongest signal power on the detection surface. However, it is possible to employ more than two channels with the proposed method for further improvement. Also, employment of co-located transmitters eliminates the need to align signals before linear summation. It is also thought that the proposed method can be used in performance critical passive radar systems because it does not negatively affect real-time signal processing performance.

\section{Acknowledgements}

This work is partially supported by the Recep Tayyip Erdogan University Scientific Research Projects Department under grant 2014.109.05.01.

\section{References}

[1] Tuysuz B, Mahmutoglu Y. "Measurement and mapping of the GSM-based electromagnetic pollution in the Black Sea region of Turkey". Electromagnetic Biology and Medicine, 36(2), 132-140, 2017.

[2] Howland PE, Maksimiuk D, Reitsma G. "FM radio based bistatic radar". IEE Proceedings-Radar, Sonar and Navigation, 152(3), 107-115, 2005.

[3] Daniel L, Hristov S, Lyu X, Stove AG, Cherniakov M, Gashinova M. "Design and validation of a passive radar concept for ship detection using communication satellite signals". IEEE Transactions on Aerospace and Electronic Systems, 53(6), 3115-3134, 2017.

[4] Zhao Y, Zhao Y, Zhao C. "A novel algebraic solution for moving target localization in multi-transmitter multireceiver passive radar". Signal Processing, 143, 303-310, 2018.

[5] Li W, Tan B, Piechocki R. "Passive radar for opportunistic monitoring in E-health applications". IEEE Journal of Translational Engineering in Health and Medicine, 6, 1-10, 2018.

[6] Griffiths H, Baker C. "Measurement and analysis of ambiguity functions of passive radar transmissions". IEEE International Radar Conference, Arlington, USA, 9-12 May 2005.

[7] Colone F, Bongioanni C, Lombardo P. "Multifrequency integration in FM radio-based passive bistatic radar, Part I: Target detection". IEEE Aerospace and Electronic Systems Magazine, 28(4), 28-39, 2013.

[8] Zhang C, Wu Y, Wang J, Luo Z. "FM-based multi-frequency passive radar system". 2016 IEEE International Conference on Signal Processing, Communications and Computing (ICSPCC), Hong Kong, China, 5-8 August 2016. 
[9] Ginolhac G, Schmitt F, Daout F, Forster P. "Multifrequency and multistatic inverse synthetic aperture radar, with application to FM passive radar". EURASIP Journal on Advances in Signal Processing, 2010(1), 1-13, 2009.

[10] Tasdelen AS, Koymen H. "Range resolution improvement in passive coherent location radar systems using multiple FM radio channels". Waveform Diversity and Design in Communications, Radar and Sonar, The Institution of Engineering and Technology Forum, London, UK, 22 November 2006.

[11] Grayver E. Implementing Software Defined Radio. $1^{\text {st }}$ ed. New York, USA, Springer, 2012.

[12] Ettus Research. "USRP N210 datasheet". https://www.ettus.com/content/files/07495_Ettus_N20 0-210_DS_Flyer_HR_1.pdf (12.05.2018).

[13] GNURadio. "GNU Radio Manual and C++ API Reference Documentation". https://gnuradio.org/doc/doxygen/index.html (12.05.2018).

[14] Malanowski M, Kulpa K, Kulpa J, Samczynski P, Misiurewicz J. "Analysis of detection range of FM-based passive radar". IET Radar, Sonar \& Navigation, 8(2), 153-159, 2014.
[15] O'Hagan DW, Baker CJ. "Passive bistatic radar (PBR) using FM radio illuminators of opportunity". New Trends for Environmental Monitoring Using Passive Systems, Hyeres, France, 14-17 October 2008.

[16] Tuysuz B. "Development of semi-real time multifrequency band supported passive radar system for aerial target detection". Journal of the Faculty of Engineering and Architecture of Gazi University, 34(1), 191-199, 2019.

[17] Griffiths HD, Baker CJ, Ghaleb H, Ramakrishnan R, Willman E. "Measurement and analysis of ambiguity functions of off-air signals for passive coherent location". Electronics Letters, 39(13), 1005-1007, 2003.

[18] Stein S. "Algorithms for ambiguity function processing". IEEE Transactions on Acoustics, Speech, and Signal Processing, 29(3), 588-599, 1981.

[19] Edelson RA, Krolik JH. "The discrete correlation functionA new method for analyzing unevenly sampled variability data". The Astrophysical Journal, 333, 646-659, 1988.

[20] Gomez-del-Hoyo P, Barcena-Humanes JL, del-Rey-Maestre N, Rosado-Sanz J, Jarabo-Amores MP. "Study of the ghost target phenomenon on a real DVB-T passive radar scenario". Signal Processing Symposium (SPSympo), Debe, Poland, 12-14 September 2017. 